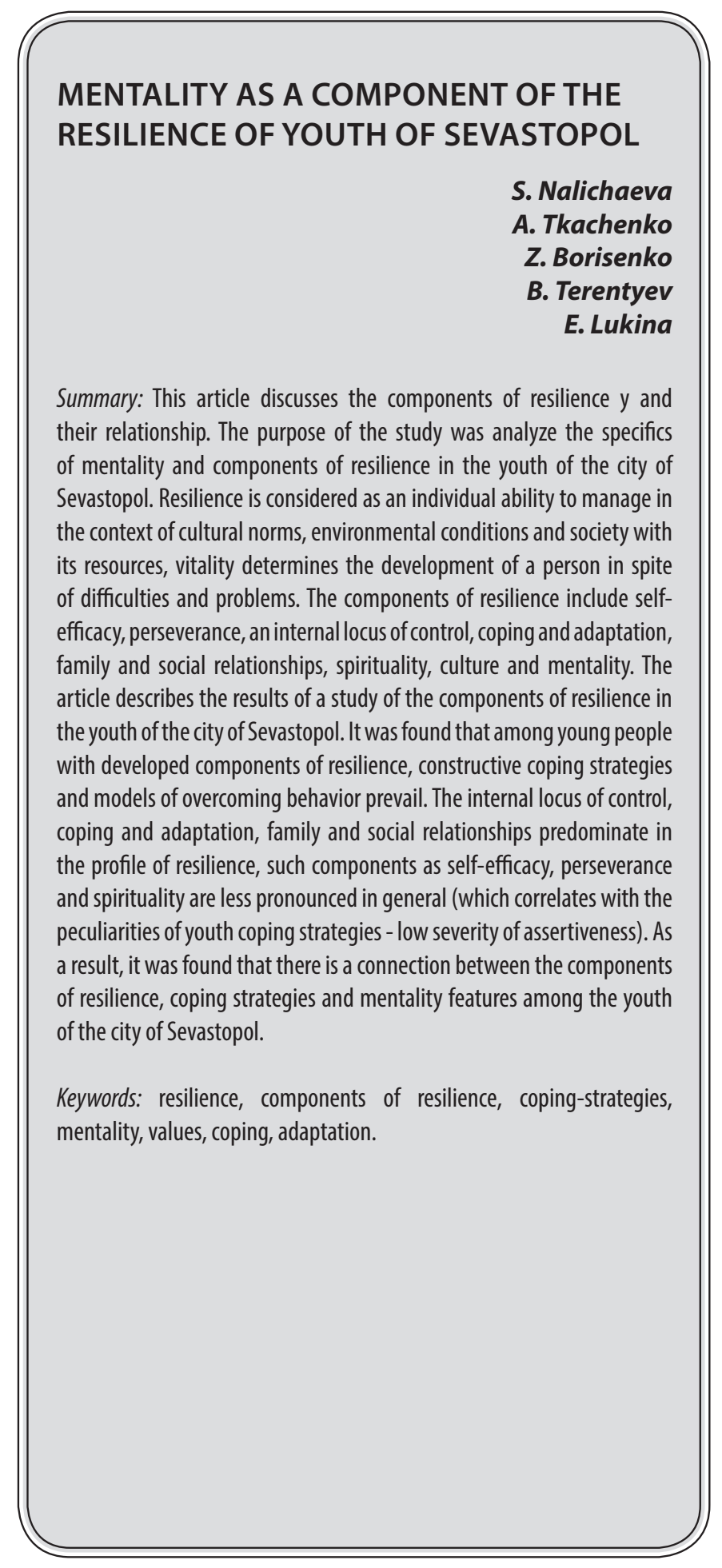

\section{Наличаева София Александровна}

K.nсх.н., дочент, Филиал Московского государственного университета имени М.В. Ломоносова в городе Севастополе espritsn@yandex.ru

Ткаченко Анастасия Александровна психолог, Филиал Московского государственного университета имени М.В. Ломоносова в городе Севастополе anastasiyaderzhavina93@mail.ru

Борисенко Зинаида Викторовна

старший преподаватель, Филиал Московского государственного университета имени М.В. Ломоносова в городе Севастополе bzvpost@gmail.com

Терентьев Богдан Игоревич

Филиал Московского государственного университета имени М.В. Ломоносова в городе Севастополе

tbogdan@mail.ru

Лукина Екатерина Максимовна

Филиал Московского государственного университета имени М.В. Ломоносова в городе Севастополе

lookinaketrin21@yandex.ru

Аннотация: В данной статье рассматриваются компоненты жизнеспособности и их взаимосвязи. Целью исследования являлся анализ специфики ментальности и компонентов жизнеспособности у молодежи города Севастополя. Жизнеспособность рассматривается, как индивидуальная способность к управлению в контексте культурных норм, условий среды и социума своими ресурсами, жизнеспособность определяет развитие человека вопреки трудностям и проблемам. К компонентам жизнеспособности относятся самоэффективность, настойчивость, внутренний локус контроля, совладание и адаптация, семейные и социальные взаимосвязи, духовность, культура и ментальность. В статье описаны результаты исследования компонентов жизнеспособности у молодежи города Севастополя. Получено, что у молодежи при развитых компонентах жизнеспособности, преобладают конструктивные копинг-стратегии и модели преодолевающего поведения. В профиле жизнеспособности преобладает внутренний локус контроля, совладание и адаптация, семейные и социальные взаимосвязи, менее выражены в целом такие компоненты, как самоэффективность, настойчивость и духовность (что соотносится с особенностями копинг-стратегий у молодежи - низкой выраженностью ассертивности). В результате получено, что существует связь компонентов жизнеспособности, копинг-стратегий и особенностей ментальности у молодежи города Севастополя.

Ключевые слова: жизнеспособность, компоненты жизнеспособности, копингстратегии, ментальность, ценности, совладание, адаптация.

Исследование выполнено при финансовой поддержке РФФИ и Правительства города Севастополя. Проект «Ментальность как компонент жизнеспособности жителей Севастополя», № 20-413-920002 p_a 
A ктуальность темы исследования определяется рядом факторов. Во-первых, жизнеспособность является одним из важнейших ресурсов развития человека, условием социальной адаптации личности включения личности во взаимодействие с социальной средой [1]. Данное понятие трактуется как способность человека к самостоятельному развитию, адаптации к окружающей среде, саморегуляции, самоактуализации. Во-вторых, в современном мире остро стоит вопрос о сохранении психического и физического здоровья человека в стрессогенных условиях. Жизнеспособность является важным фактором адаптации в условиях неопределенности и дефицита времени в современном мире. В данных условиях жизни важнейшей задачей человека является формирование умения бороться с негативными факторами среды. А.В. Махнач определяет жизнеспособность как индивидуальную способность к управлению в контексте культурных норм, условий среды и социума своими ресурсами: волевой, мотивационной, эмоциональной и когнитивной сферами. А.В. Махнач выделил шесть компонентов жизнеспособности: самоэффективность, настойчивость, локус контроля, совладание и адаптацию, духовность, семейные и социальные взаимоотношения. В состав самоэффективности входят представления и ожидания личности, способность «активировать» когнитивную и мотивационную сферы. Настойчивость характеризует желание и способность индивида к борьбе за баланс, вопреки неблагоприятным воздействиям, синонимом данного понятия является упорство. Внутренний локус контроля отвечает за то, что человек оказывает влияние на собственную жизнь и жизнь окружающих его людей, ответственность за то, что с ним происходит лежит на нем самом, никто из «вне» не является причиной его успехов или неудач. В состав жизнеспособности входят совладание (стратегии поведенческой и когнитивной сфер личности) и адаптация (приспособление) к изменяющимся или неблагоприятным обстоятельствам. Компонентами жизнеспособности являются семейные (социальные) взаимосвязи как система поддержки на пути совладания со стрессом. Значимым компонентом жизнеспособности является духовность в аспекте религиозности (обращение человека к «высшей силе» в трудных жизненных обстоятельствах) [8]. Кроме этого, составляющими жизнеспособности человека являются нравственность, духовность, ментальность и культура. Жизнеспособность связана с понятием индивидуальности человека. Согласно концепции интегральной индивидуальности В.С. Мерлина, существуют три уровня свойств индивидуальности: свойства организма, психодинамические свойства и социально-психологические свойства. На уровне организма особенности биохимических и общесоматических свойств индивидуальности человека формируют его уникальность. Нейродинамические свойства характеризуют скорость возникновения, развития и протекания нервных процессов, их силу, лабильность. В системе индивидуально-психи- ческих свойств представлены темперамент и особенности личности, характеризующие устойчиво проявляющиеся динамические особенности поведения человека. На уровне социально-психологических свойств индивидуальности, рассматриваются особенности социального и личностного статуса человека: принадлежность к большим группам (страна, этнос), социально-историческим общностям, конкретным социальным группам (семья, трудовой коллектив) [10]. Так, жизнеспособность и ее компоненты формируются с учетом свойств интегральной индивидуальности на всех уровнях. Существует различные определения жизнеспособности: так, с одной стороны, жизнеспособность - индивидуальная интеграция всех систем ресурсов человека, обеспечивающих его успешную адаптацию, а, с другой - индивидуальная способность человека управлять собственными ресурсами в контексте социальных, культурных норм и средовых условий [4]. Жизнеспособность рассматривается и как способность человека или социальной системы строить нормальную, полноценную жизнь в трудных условиях, жить и развиваться вопреки тяжелым и травматическим событиям. Жизнеспособность может находиться в латентном состоянии, но из-за различных событий, происходящих в жизни человека - активизироваться [6]. Результатом процесса перехода человека из пассивного состояния в активное является позитивное развитие человека в тяжёлой жизненной ситуации [2]. Этот процесс соотносится с понятием посттравматического роста. Совладание с трудной ситуацией в случае посттравматического роста - это рост, который выводит человека на новый уровень, открывая перед ним новые горизонты [7]. Жизнеспособная личность характеризуется умением самостоятельно решать жизненные проблемы, преодолевать жизненные невзгоды, обладает ответственностьюидобросовестностью[3].Жизнеспособность соотносится со способностью человека преодолевать трудности, что характеризует механизм совладания. Способность субъекта воспроизводить себя, свою культуру, свои отношения вопреки опасностям и проблемам является характеристикой жизнеспособности человека. Жизнестойкость является внутренним потенциалом личности, в то время, как жизнеспособность (личностные и социальные факторы) - более широкий социально-психологический потенциал человека. Следовательно, среди компонентов жизнеспособности можно выделить самореализацию человека, а личностный самоактуализационный потенциал можно рассматривать, как ресурс жизнеспособности. Самоактуализация и связанные с ней ценностно-смысловые особенности личности, мотивы, особенности самоотношения и отношения к жизни и профессии взаимосвязаны между собой и составляют интегральную характеристику развития личности - личностный самоактуализационный потенциал [11]. Жизнеспособность - социально-психологический феномен, отражающий устойчивость личности и группы к меняющимся условиям жизнедеятельности, а жизне- 
способность группы - это отношение членов группы к неблагоприятным условиям совместной жизнедеятельности, к совместной деятельности, направленной на защиту от коллективных угроз, и использование возможностей для развития группы. Т.А. Нестик выделяет следующие компоненты групповой жизнеспособности как социально-психологического феномена: ценностномотивационные (групповые цели, ценности, групповое доверие), когнитивные (позитивная групповая идентичность, образ коллективного будущего, групповая самоэффективность, коллективная память о совместном преодолении трудностей, представления о совместной деятельности в кризисных условиях), аффективные (оптимизм), поведенческие (нормы, регулирующие просоциальное поведение, взаимную поддержку, организациювнутригруппового имежгрупповоговзаимодействия в кризисных ситуациях; ориентация на нормы, поддерживающие эмоциональную саморегуляцию группы) [12]. Важными компонентами жизнеспособности человека являются: способность любить, быть любимым, созидательная автобиографическая память, конструктивное, целостное мышление [15]. К компонентам жизнеспособности относятся культура и ментальность человека. Под ментальностью в данной работе понимается относительно устойчивая совокупность установок и предрасположенностей индивида или социальной группы воспринимать мир определенным образом. Ментальность формируется в зависимости от традиций культуры, социальных структур и всей среды жизнедеятельности человека, и сама их формирует, выступая как порождающее начало, как трудноопределимый исток культурно-исторической динамики [13]. Ментальность человека определяет вектор его развития, особенности отношения к достижениям и проблемам, к стресс-факторам внешней среды. Понятие ментальности имеет социально-психологические и культурные корни. Культура - основа ментальности и системообразующий фактор развития жизнеспособности. Так, закрепленные на уровне культуры способы отношения, рефлексии, переживания и действия при возникновении определенных проблем предопределяют адаптацию и способность развиваться вопреки трудностям. Культура является компонентом жизнеспособности человека, общественным продуктом определенного этапа развития общества, она проявляется в передаваемых из поколения в поколение ценностях, символах, верованиях, паттернах поведения, общественных нормах, которые определяют духовную жизнь народа. Жизнеспособность общества определяется его открытостью опыту, среде, предполагает культурную перспективу, так как связана с социально-культурными элементами жизни, передачей культурных ценностей. Преемственность культурных ценностей повышает жизнеспособность каждого поколения, а их потеря ведет к снижению жизнеспособности, утрата ценностей ведет к снижению качества жизни, потере ее смысла [8]. Ментальность имеет следующие особенности:
- характеризует уровни индивидуального и коллективного сознания, определяя специфический тип мышления, формируется на основе природно и социально обусловленных факторов, имеет достаточно устойчивый характер; - форма осознания окружающего мира, общества, формируемая в ходе осмысления социального опыта индивидуальным и коллективным сознанием, выражающая актуальные для данного коллектива ценности;

- влияет на общественные отношения, является устойчивой настроенностью общества, объединяет людей, включает в себя совокупность установок и предрасположенностей людей к определенному типу мышления и действия;

- выступает как результат культуры и традиций, и сама является глубинным источником развития культуры.

С помощью ментальности в настоящее время трактуют определенный образ мыслей, привычки, пристрастия, коллективные эмоции [14]. Ментальность может рассматриваться на разных уровнях субъектности: ментальность индивида, территориальной общности (города), этноса, народа, большой социальной группы, страны [9]. Ментальность имеет определенную структуру, включает в себя: качества личности человека (коммуникабельность, доминантность, доброжелательность, стили мышления и принятия решения), мотивационной сферы (мотивы, интересы), особенности эмоциональной сферы личности (эмоции, настроения), ценности и смыслы, нравственно-духовные особенности, социальный и культурный опыт и т.д. Ментальность - философско-психологическая категория, характеризующая своеобразие миропонимания, присущее человеческим объединениям: этносам, территориальным и местным общностям, социальным и профессиональным группам, коллективам. А менталитет - образ мира в сознании отдельного индивида - члена конкретной группы [5]. Ментальность и менталитет могут представлять разные уровни группового сознания: ментальность - более «поверхностный» (осознаваемый) уровень, а менталитет - более «глубинный» (неосознаваемый, подсознательный). Менталитет является фундаментальным уровнем, а ментальность более изменчива [9]. Субъектом ментальности является сам индивид, ментальность состоит из функциональных единиц (образов, представлений, установок, ценностей) и ментальных операций (способа классификации, рассуждения и аргументации, соотношения рефлексии и саморефлексии), объединяя в себе сознательное и бессознательное. Г.В. Акопов рассматривает ментальность как групповое сознание, детерминированное пространственно-временными особенностями жизнедеятельности группы. Главные функции ментальности с точки зрения общности включают в себя закрепление групповых особенностей, выражение и утверждение групповых интересов и ценностных ориентаций. Важной функцией 
ментальности как группового сознания является взаимопонимание индивидов, составляющих общность.

Объект исследования: жизнеспособность человека. Предмет исследования: ментальность как компонент жизнеспособности человека. Цель исследования: проанализировать специфику ментальности и компонентов жизнеспособности у молодежи города Севастополя. Гипотеза: существует связь компонентов жизнеспособности, копинг-стратегий и особенностей ментальности у молодежи города Севастополя. В исследовании использованы следующие теоретические методы; психодиагностическое тестирование: «Стратегии преодоления стрессовых ситуаций» (С. Хобфолл, 1994); тест «Жизнеспособность взрослого человека» (А.В. Махнач, 2017); анкетирование с использование авторской анкеты анализа особенностей ментальности. Исследование проведено на выборке из 80 человек (молодежь города Севастополя, в возрасте от 20 до 36 лет (40 мужчин и 40 женщин)). При помощи опросника «Стратегии преодоления стрессовых ситуаций» описана специфика стратегии и моделей копинг-поведения. Тест «Жизнеспособность взрослого человека» позволил описать компоненты жизнеспособности. Авторская анкета анализа особенностей ментальности включала в себя 45 вопросов, входящих в следующие блоки: социально-демографический блок; качества личности; идентификация; представления; ценности; когнитивные особенности; мотивация; морально-нравственные; экзистенциальные; эмоциональные и коммуникативный компонент; отношение к риску; отношение ко времени. Полученные данные обработаны с использованием статистических методов (анализ статистической значимости различий по показателям жизнеспособности, копинг-стратегий и ментальности между подгруппами молодежи, выделенными по возрасту, полу, семейному положению, роду занятий, профессии (направлению подготовки); анализа корреляционных связей показателей при помощи r-Пирсона). В результате диагностики получено, что для молодежи характерно использование следующих стратегии и моделей копингповедения: вступление в социальный контакт и поиск социальной поддержки (72\% выборки), импульсивные действия (15\%), манипулятивные (непрямые) действия (9\%) и другие стратегии (4\%). Анализ средних значений по шкалам моделей преодолевающего поведения показал, что наиболее характерными для молодежи являются просоциальные стратегии (поиск социальной поддержки и вступление в социальный контакт). Активные, просоциальные стратегии преодолевающего поведения у молодежи являются конструктивными, в связи с тем, что в ситуации стресса и неопределенности студенты и молодые специалисты склонны обращаться за поддержкой к друзьям, коллегам, семье, имея возможность конструктивно отреагировать негативные эмоции, получить поддержку и помощь, новый опыт в процессе коммуникации. Особенностью небольшой части данной выборки молодежи является использование импульсивных действий для преодоления стресса, что не относится к конструктивной стратегии совладания со стрессом, данная особенность может соотноситься с возрастом испытуемых и с особенностями их личности. В целом, для данной выборки молодежи не характерно использование неконструктивных стратегий: агрессивные, осторожные действия, однако, отмечаются испытуемые с преобладанием такой копинг-стратегии, как манипулятивные (непрямые) действия, что является неконструктивной особенностью при совладании со стрессом, так как непрямые стратегии часто не приводят к преодолению стрессовой ситуации, а, напротив, осложняют процесс разрешения стрессовой ситуации. Интересной особенностью копинг-стратегий молодежи является низкая выраженность ассертивности и уверенности в себе в контексте совладания со стрессом, что может соотноситься с недостаточно конструктивным копингом в случае стресса в процессе обучения и профессиональной деятельности. Анализ особенностей копинг-стратегий в подгруппах молодежи разного возраста, пола, с различным семейным положением, обучающих и работающих, разных профессий и направлений подготовки (с использованием U-критерия Манна-Уитни) показал следующие различия:

- у юношей более выражена импульсивная копингстратегия, чем у девушек ( $p<0,05)$, а у девушек более выражена манипулятивная копинг-стратегия, чем у юношей ( $p<0,05)$, значимых различий в проявлении просоциальных стратегий не выявлено;

- выраженность импульсивной копинг-стратегии статистически значимо выше у молодежи младшей подгруппы (в возрасте 20 - 25 лет), чем у молодежи старшей подгруппы (от 31 до 36 лет) $(p<0,01)$, статистически значимо выше показатели просоциальных стратегий у молодежи средней по возрасту подгруппы (26 - 30 лет) ( $<<0,01)$;

- интересно, что между подгруппами молодежи с разным семейным положением не выявлено значимых различий в копинг-стратегиях, это говорит о гибкости в проявлении поиска социального контакта и социальной поддержки в родительской семье, в собственной семье, в кругу коллег и друзей.

В результате диагностики компонентов жизнеспособности было получено, что для молодежи характерны высокие уровни всех компонентов жизнеспособности. В профиле жизнеспособности у молодежи преобладает внутренний локус контроля, совладание и адаптация, семейные и социальные взаимосвязи, менее выражены в целом такие компоненты, как самоэффективность, настойчивость и духовность (что соотносится с особенностями копинг-стратегий - низкой выраженностью ассертивности). Особенности жизнеспособности молодежи выражаются в преобладании представления о том, что они являются ответственными за происходящее в их 
жизни, могут влиять на окружение и ход жизни в будущем, оптимистичности по поводу способности находить позитивные решения для самих себя и других людей, обладают когнитивными и поведенческими стратегиями для управления потребностями в неблагоприятных условиях, приспособлением к изменяющимся или неблагоприятным обстоятельствам; уверенностью в том, что он может успешно совладать с неблагоприятными условиями; использованием эмоционально-ориентированных и направленных на решение проблем стратегий; оценки межличностных связей, как важного источника эмоциональной поддержки, являющегося основанием жизнеспособности, способности индивида использовать семью, социальную и любую внешнюю систему поддержки для лучшего совладения со стрессом. Получено что, для молодежи не характерна вера в высшие силы, однако, свойственны проявления духовности, как внутреннего регулятора жизнедеятельности, снижающего уровень неудовлетворенности собой и делающего более осмысленной жизнь. У молодежи достаточно развиты такие компоненты жизнеспособности, как самоэффективность и настойчивость, так, для молодежи характерны ожидания и представления, вера в свою способность мобилизовать мотивацию, когнитивные ресурсы, и действия для оказания влияния на то или иное событие, адекватная самооценка, вера в свою эффективность, тогда как несколько ниже показатели настойчивости, что выражается в средних показателях упорства, живучести, самодисциплины, желания продолжить борьбу за восстановление баланса после воздействия неблагоприятных событий жизни. Анализ различий компонентов жизнеспособности в подгруппах молодежи разного возраста, пола, с различным семейным положением, обучающих и работающих, разных профессий и направлений подготовки (с использованием U-критерия МаннаУитни) показал следующие различия:

- у юношей более выражена настойчивость, чем у девушек ( $<<0,05)$, а у девушек более выражены самоэффективность, семейные и социальные взаимосвязи, чем у юношей $(p<0,05)$, значимых различий в проявлении внутреннего локуса контроля, адаптации и совладания, духовности не выявлено;

- выраженность совладания и адаптации статистически значимо выше у молодежи старшей подгруппы (в возрасте 31 - 36 лет), чем у молодежи младшей подгруппы (от 20 до 25 лет) (р<0,05), статистически значимо выше показатели настойчивости у молодежи средней по возрасту подгруппы (26-30 лет) $(p<0,05)$;

- между подгруппами молодежи с разным семейным положением выявлены различия в проявлении семейных и социальных взаимосвязях, духовности, так у молодежи, живущей в родительской семье и имеющих свою семью данные показатели статистически значимо выше $(r<0,01)$.
В результате анкетирования молодежи при помощи авторской анкеты анализа особенностей ментальности получено, что все испытуемые выборки родились в городе Севастополе и живут в нем на протяжении всей жизни, относятся к разным профессиональным группам, таким, как: инженеры, военнослужащие, педагоги, торговые работники, социальные работники, менеджеры, переводчики, спасатели, медицинские работники, психологи, журналисты, студенты различных направлений подготовки. Испытуемые отметили, что считают себя севастопольцами, для которых характерны такие качества личности, как небезразличие, активность, умение терпеть, закрытость, смелость, решительность. По мнению респондентов, к хорошим людям относятся те люди, которые обладают пониманием и состраданием, умеющие помогать, умеющие хранить тайны и верные своим идеалам, имеющие свои принципы, верные, честные, не склонные к предательству. По мнению респондентов, к плохим людям относятся предатели, злые люди, люди, не имеющие принципов, безразличные, ленивые, жестокие люди. Большинство испытуемых считают, что могут влиять на ход событий в жизни, могут управлять своей жизнью, что соотносится с результатами диагностики компонентов жизнеспособности. Из предложенных в анкете качеств испытуемые наиболее высоко оценили (соотнесли со своей личностью): готовность прийти на помощь, порядочность, добросовестность, доброжелательность, целеустремленность, стремление быть с родными людьми, осуществление смысла в жизни (стремление к пониманию смысла), стремление к достижению успеха, достижения блага для окружающих, стремление понимать других, умение сочувствовать, сострадать, потребность делать добро, замкнутость, смелость, трудолюбие. А окружающих людей оценили, как общительных, оптимистичных, целеустремленных, но стремящихся жить сегодняшним днем, склонных рисковать, любящих праздники, настойчивых, предприимчивых. Расхождение в списках качеств, описывающих себя и других, может отражать конфликт в сфере ценного и доступного, своих стремлений и ожиданий от других людей, так, себя респонденты описывают, как более замкнутых, сдержанных, готовых прийти на помощь, надежных и целеустремленных, а окружающих, как более общительных и открытых, склонных к риску, предприимчивых, любящих праздники. Респондентам характерно некоторое недоверие людям, больший процент группы молодежи отмечает, что, не зная человека, не доверяет ему, не верит в то, что может повлиять на него, тогда как 1/3 выборки отмечает, что, не зная человека на работе, считает, что ему можно доверять, верит в то, что может влиять на его отношение. Среди ценностей респонденты отметили: здоровье, развитие, свободу, время, помощь, дружбу, семью, любовь, духовное удовлетворение, материальный достаток. Респонденты отметили, что будут стремиться хорошо работать, если будут знать, что, то, что они делают на работе нужно людям, интересно окружающим и им 
самим, может быть полезно окружающим, сформирует новый опыт и будет оплачиваться. Анализ мотивации и ценностей выборки молодежи Севастополя показал, что у респондентов преобладают духовные ценности над материальными и среди мотивов преобладают внутренние над внешними. Только 6\% группы представителей молодежи города Севастополя отмечают, что, когда им плохо (грустно, страшно), они стремятся остаться наедине с собой для того, чтобы осмыслить ситуацию и поведение, тогда как 74\% респондентов отмечают, что стремятся разделить свои переживания с окружающими, получить поддержку у семьи, друзей, коллег, в некоторых случаях, знакомых людей, и 30\% респондентов отмечают, что стремятся разделить свое состояние и поделиться с крайне узким кругом людей - любимым человеком, мужем (женой), мамой или папой, сестрой или братом, одним другом (подругой). Некоторые респонденты отмечают, что если им предложили дело, о котором они не знают ничего, они возьмутся за него, так как им сложно отказать людям (12\%), большая часть группы отмечает, что если им предложили дело, о котором они не знают ничего, возьмутся за него, так как во всем можно разобраться (52\%); $20 \%$ респондентов отмечают, что если им предложат дело, о котором они не знают ничего, то они не возьмутся за него, так как не любят ситуации неопределенности и недостатка информации; 16\% респондентов отмечают, что, если им предложат дело, о котором они не знают ничего, они не возьмутся за него, пока им подробно не расскажут о нем, не покажут необходимую документацию. Большинство респондентов не склонны К прокрастинации при выполнении большого объема работы, однако, немногие склонны и планировать дела, небольшой процент испытуемых стремятся выполнять большой объем работы весь сразу перед самым сроком сдачи. Анализ корреляционных связей показателей копинг-стратегий, компонентов жизнеспособности, особенностей ментальности при помощи r-Пирсона показал, что интегральный показатель жизнеспособности связан с такими качествами личности молодежи, как готовность прийти на помощь $(r=0,6, p<0,01)$, оптимизм $(r=0,5, p<0,01)$, уверенность в себе $(r=0,6, p<0,01)$, порядочность $(r=0,7, p<0,01)$, целеустремленность $(r=0,6$, $\mathrm{p}<0,01)$, умение ограничивать себя $(r=0,4, p<0,05)$, peшительность $(r=0,6, p<0,01)$, смелость $(r=0,7, p<0,01)$, трудолюбие $(r=0,6, p<0,01)$, замкнутость $(r=-0,7, p<0,01)$. Жизнеспособность связана с ценностями свободы $(r=0,6, p<0,01)$, здоровья $(r=0,6, p<0,01)$, развития $(r=0,7$, $\mathrm{p}<0,01)$, семьи $(r=0,7, p<0,01)$. Жизнеспособность связана с представлениями молодежи о хорошем человеке, как о том, который обладает пониманием и состраданием $(r=0,7, p<0,01)$, умеет помогать $(r=0,6, p<0,01)$. Жизнеспособность связана с поиском социальной поддержки $(r=0,7, p<0,01)$, вступлением в социальный контакт $(r=0,7$, $p<0,01)$, манипулятивными действиями $(r=-0,5, p<0,01)$, острожными действиями $(r=-0,5, p<0,01)$.

Таким образом, жизнеспособность - индивидуальная способность к управлениюв контексте культурных норм, условий среды и социума своими ресурсами, развитие человека вопреки трудностям и проблемам. К компонентам жизнеспособности относятся самоэффективность, настойчивость, внутренний локус контроля, совладание и адаптация, семейные и социальные взаимосвязи, духовность, культура и ментальность. У молодежи города Севастополя при развитых компонентах жизнеспособности, преобладают конструктивные копинг-стратегии, а среди коррелятов жизнеспособности выделяются готовность прийти на помощь, оптимизм, уверенность в себе, порядочность, целеустремленность, умение ограничивать себя, решительность, смелость, трудолюбие, ценности свободы, здоровья, развития, семьи. Жизнеспособность связана с представлениями молодежи о хорошем человеке, как о том, который обладает пониманием и состраданием, умением помогать, с поиском социальной поддержки, вступлением в социальный контакт. Таким образом, существует связь компонентов жизнеспособности, копинг-стратегий и особенностей ментальности у молодежи города Севастополя.

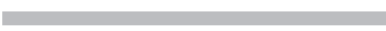

ЛИТЕРАТУРА

1. Ананьев Б.Г. Человек как предмет познания. СПб.: Питер. 2010. 288 с.

2. Гозман Л.Я. Психология эмоциональных отношении [Текст]. М.: МГУ, 1987. 175 с.

3. Гурьянова М.П. Воспитание жизнеспособной личности в условиях дисгармоничного социума // Педагогика. 2004. № 1. С. 12-18.

4. Ильин Е.П. Эмоции и чувства [Текст]. 2-е изд. СПб.: Питер, 2013. 783 с.

5. Курсикова Я.А. Менталитет как многогранная психологическая характеристика индивида // Ежегодник РП0: Материалы Третьего Всероссийского съезда психологов, 25-28 июня 2003 г.: в 8 тт. Т. 4. СПб., 2003. С. 576-579.

6. Лактионова А.И. Жизнеспособность В структуре психологических понятий [электронный ресурc]: URL: https://vestnik-mgou.ru/Articles/Doc/2642 (дата обращения 01.06.2020)

7. Магомед-Эминов М.Ш. Феномен посттравматического роста // Вестник ТГУ, выпуск 3 (71), 2009. С. 111-117

8. Махнач А.В. Жизнеспособность человека и семьи: социально-психологическая парадигма. М.: «Институт психологии РАН», 2016. С.135-204.

9. Ментальность как групповое сознание: учебное пособие по курсу «Психология ментальности»: для магистратуры по психологическим направлениям / Г.В. Акопов, Л.В. Давыдкина, Т.В. Семенова. Самара: ПГСГА, 2015. 76 с. 
10. Мерлин В.С. Очерк интегрального исследования индивидуальности. - М.: Педагогика, 1986. 256 с.

11. Наличаева С.А. Самоактуализационный потенциал личности как детерминанта профессионального выгорания педагогов: диссертация ... кандидата психологических наук. Москва, 2011. 247 с.

12. Нестик Т.А. Жизнеспособность социальной группы: основные подходы к изучению // Жизнеспособность человека: индивидуальные, профессиональные и социальные аспекты / Отв. ред. А.В. Махнач, Л.Г. Дикая. М.: Изд-во «Институт психологии РАН». 2016. С. 176-192.

13. Новая философская энциклопедия: В 4 тт. М.: Мысль. Под редакцией В.С. Стёпина. 2001.

14. Проблема ментальности: Межкафедральный сборник научных трудов. Курган: Изд-во Курганского гос. ун-та, 2011. 134 с.

15. Рыльская Е.А. Психологические детерминанты жизнеспособности человека: онтологический контекст // Вестник ЧГПУ. 2009. № 8. С. 87-96

( ) Наличаева София Александровна (espritsn@yandex.ru), Ткаченко Анастасия Александровна (anastasiyaderzhavina93@mail.ru), Борисенко Зинаида Викторовна (bzvpost@gmail.com), Терентьев Богдан Игоревич (tbogdan@mail.ru),

Лукина Екатерина Максимовна (lookinaketrin21@yandex.ru).

Журнал «Современная наука: актуальные проблемы теории и практики»

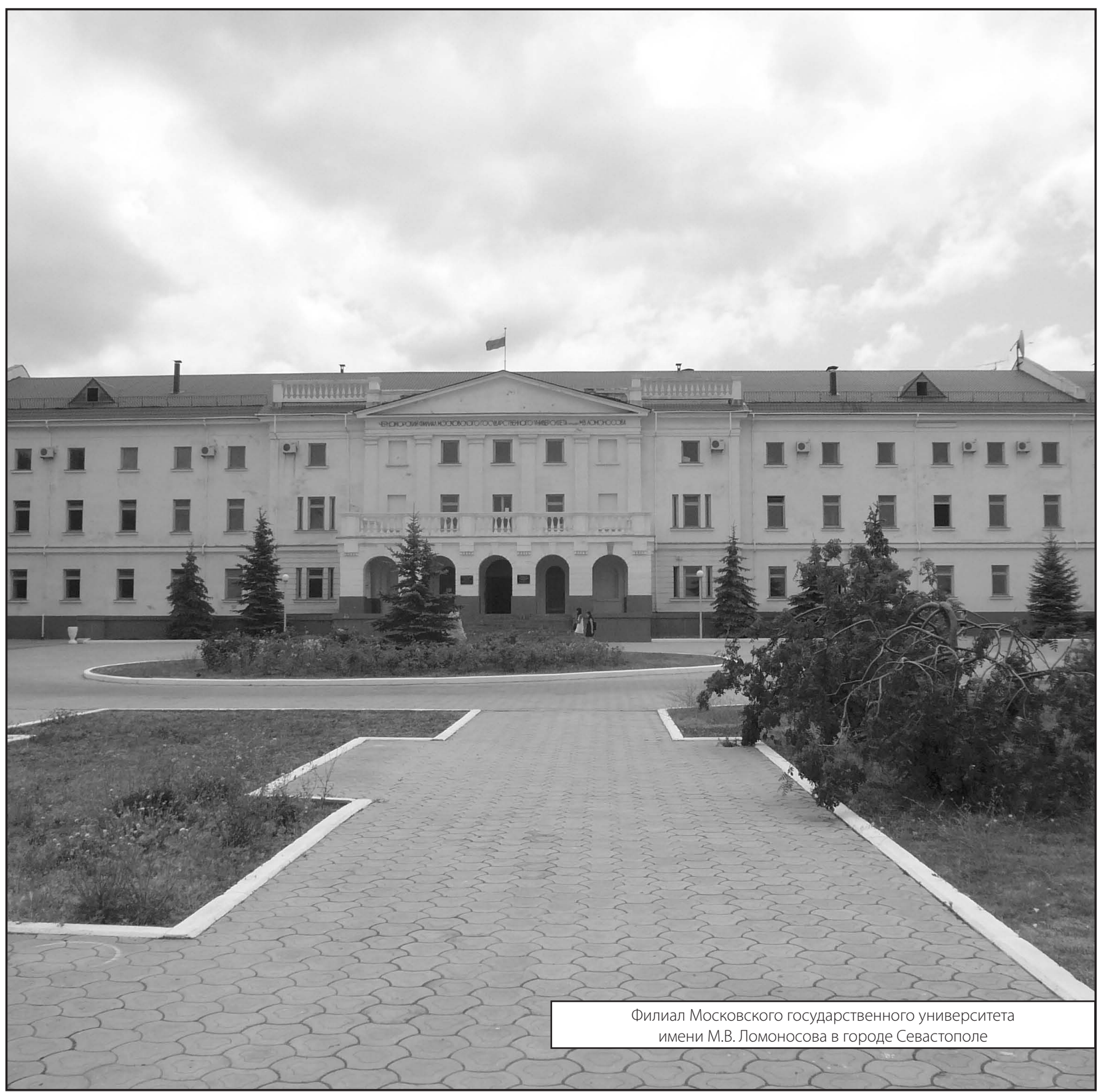

